\title{
Research on the Spatial Pattern of National Landscape Garden Counties
}

\author{
Han Jing \\ College of Urban and Environmental Sciences \\ Northwest University \\ Xi'an710127, China \\ hjxbdx@163.com \\ Wang Xirui \\ College of Urban and Environmental Sciences \\ Northwest University \\ Xi'an710127, China
}

\author{
Ma Teng \\ College of Urban and Environmental Sciences \\ Northwest University \\ Xi'an710127, China \\ Rui Yang \\ College of Urban and Environmental Sciences \\ Northwest University \\ Xi'an710127, China
}

\author{
Zhang jian* \\ College of Urban and Environmental Sciences \\ College of Silk Road Studies \\ Northwest University \\ Xi'an710127, China \\ Xi'an710069, China
}

\begin{abstract}
Through the systematic description of the spatial pattern characteristics of the National Garden Counties, this paper enriches the research on the city spatial distribution and provides a scientific basis for the improvement of the policy of "Building Garden Cities". Comprehensively using the methods of nearest neighbor indexes, nuclear density estimation, imbalance indexes and ESDA, it systematically characterizes the spatial pattern of National Landscape Garden Counties. The results show that: (1) the spatial agglomeration of National Landscape Garden Counties are significant, and 3 high density areas are formed in the central Shandong, Southern Hebei and Western Guanzhong. (2)There is the scale effect in the distribution of National Landscape Garden Counties, which indicates the transformation from the regional scale to the provincial scale. (3) There are obvious autocorrelation features in the distribution of National Landscape Garden Counties. The core-periphery structure of the spatial association pattern is significant, and the law of the change from heat to cold and the gradient are presented.
\end{abstract}

Keywords-National Landscape Garden Counties; Spatial pattern; Spatial agglomeration; Spatial differentiation; Spatial correlation

\section{INTRODUCTION}

The national scale of urban spatial distribution is an important topic in China's urban geography since 1980s [1]. It can be seen from the literature that the academic circles have made remarkable progress in this study, which includes the deepening of the research content, including the revelation of the characteristics of the macro pattern of urban distribution in China, the analysis of evolution process and the interpretation

Sponsor: National Natural Science Foundation of China (No.41601174, No.41601177), Scientific Research Program Funded by Shaanxi Provincia Education Department (Program No.16JK1757, No.16JK1773), The Science Foundation of Northwest University (No.14NW03, No.15NW02)

Corresponding author: Email: zhangjian@nwu.edu.cn of the mechanism of influence. The research methods have been improved continuously, including descriptive statistics, thematic maps, nearest neighbor analysis, center of gravity model [2] and grid analysis [3]. The application of spatial autocorrelation analysis [4], GIS spatial analysis method [5] and geostatistical methods [6] have increased significantly in the last 10 years. The time span of research extends from 100 years [7] to the whole feudal society of China [6]. Data sources are expanded from statistical yearbooks to historical documents [6] and night lighting data [8]. However, it is also necessary to know that the results are mainly focused on the cities of different levels [4], and the analysis of the towns, especially the county towns [9-10], is relatively inadequate, and lack of the discussion of the specific types of cities, such as National Landscape Garden County [11]. In view of this, the National Landscape Garden County town in the national garden city series is taken as an example. By using the nearest neighbor index, nuclear density estimation, unbalance index and ESDA, the spatial agglomeration pattern, distribution pattern and association pattern are systematically depicted in order to expand the content of urban spatial distribution research and provide scientific basis for the perfection of "creation garden" policy. 


\section{DATA AND METHODOLOGIES}

\section{A. Data}

The research samples are 291 National Landscape Garden County named by the end of 2017. The analysis units are 31 provinces in the mainland of China with national garden counties. The sample data came from the website of the Ministry of Housing and Urban-Rural Development (http://www.mohurd.gov.cn), and the spatial cdata ame from the National Basic Geographic Information Center (http://ngcc.sbsm.gov.cn). With the help of the Baidu map API, the spatial location information of National Landscape Garden County is obtained and approved by xGeocoding software. ArcGIS10.2 software was used to visualize the distribution of National Landscape Garden County (Fig. 1).

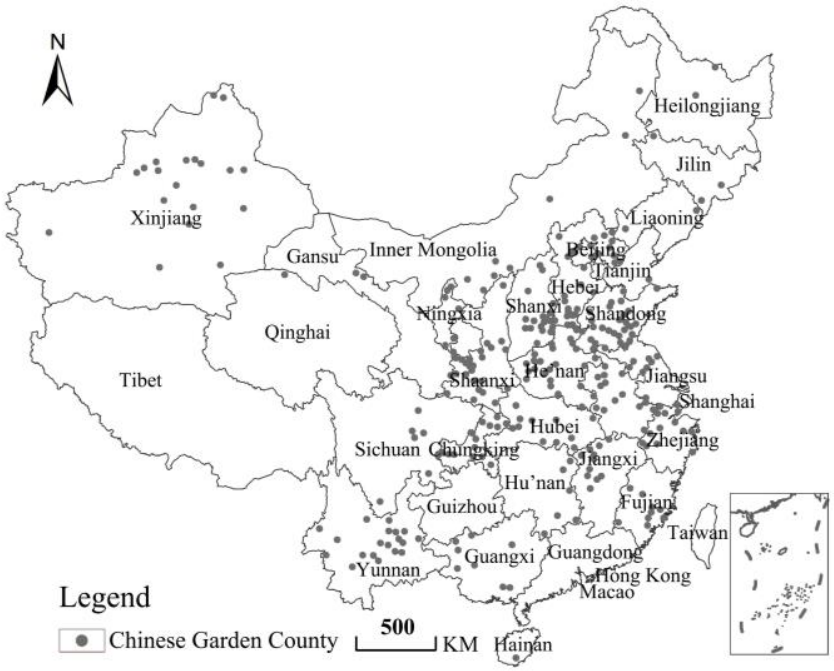

Fig. 1 The Spatial Distribution of National Landscape Garden Counties

\section{B. Methodologies}

(1) Nearest neighbor index. It is a geographical index that represents the proximity and relationship between dots and can be used to measure the spatial distribution pattern of National Landscape Garden County. The calculation formula is detailed in reference [12]. When NNI < 1, the elements present a spatial aggregation pattern; when NNI $=1$, the elements are randomly distributed; when NNI >1, the elements are uniform distributed.

(2) Kernel density estimation. It has been widely used in the study of geographical elements distribution, which can directly reflect the spatial agglomeration area of National Landscape Garden County and can be obtained by using the Kernel Density tool in the ArcGIS. The calculation formula is detailed in reference literature [11]. In this study, bandwidth has been identified as $200 \mathrm{~km}$ after many tests.

(3) Imbalance index. It can characterize the equilibrium degree of National Landscape Garden County in different spatial scales distribution. The calculation formula is detailed in reference literature [12]. The index value is $[0,1]$, if $=0$, it indicates that the average distribution of National Landscape Garden County in different areas. If $=1$, it indicates that National Landscape Garden County are concentrated in one area.
(4) ESDA. It takes the spatial correlation measure as the core, and the representative tools have Global Moran's I, Moran scatter plot and Getis-Ord Gi* indices. The calculation results of the former and the latter two can reflect the spatial correlation characteristics of National Landscape Garden County in the global and local areas respectively. The specific formulas refer to the literature [4] and [11].

\section{RESULTS AND ANALYSIS}

\section{A. Spatial agglomeration pattern of National Landscape Garden Counties}

The nearest neighbor index of National Landscape Garden County was calculated to be 0.59 , and the result passed the significance test (Fig. 2).Based on this, we can see that it has a significant spatial agglomeration pattern. Then, performed a kernel density mapping for National Landscape Garden County (Fig. 3), to explore the specific regions and pattern of spatial agglomeration. From the figure, we can see that the pattern of National Landscape Garden County is generally in the form of "Eastern is dense and Western is sparse" and a multi-centered structure; A total of three agglomeration centers are located in the eastern, central and western regions. They are located in the Luzhong, Jinan and Guanzhong western areas.

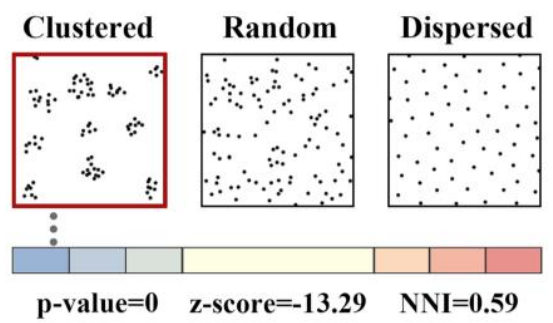

Fig. 2 Nearest Neighbor Indexes of National Landscape Garden Counties

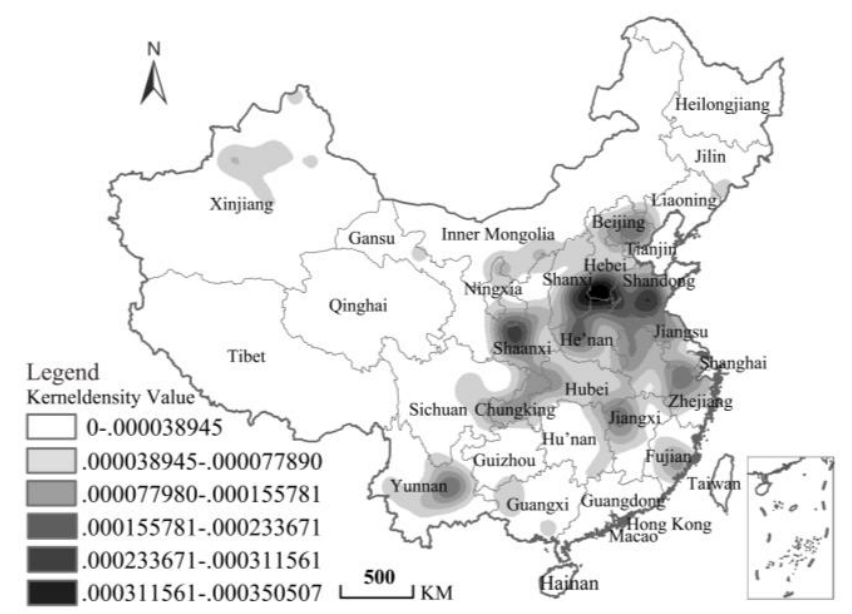

Fig. 3 The Kernel Density Map of National Landscape Garden Counties 
B. Spatial heterogeneity pattern of National Landscape Garden Counties

Statistics of the number of National Landscape Garden County counted in seven geographical regions and provincial administrative regions and calculated its proportion to the total number of the country (table1, table2). The imbalance indices at the regional and provincial scales are 0.37 and 0.52 , respectively. It shows that with the declining of research scale, the distribution of National Landscape Garden County tends to be uneven from the average. In terms of sub-regions, the number of National Landscape Garden County in the East China region is the largest, followed by the northwest and north China regions. The above three geographical regions have gathered nearly two-thirds of National Landscape Garden County .In terms of provinces, the top 10 provinces and cities are distributed in all five geographical regions except South China and Northeast China. However, the total number of National Landscape Garden County within the country has accounted for nearly $70 \%$ of the country's total .The number of National Landscape Garden County in 4 provinces of Hebei, Shandong, Henan and Shaanxi is over 20, ranking the top 4; the number of National Landscape Garden County in Beijing, Liaoning, Heilongjiang, Tianjin, Hainan and other 10 provinces are all below 3, including Shanghai, Guangdong, Guizhou, Tibet and Qinghai are even the blank areas of National Landscape Garden County.

TABLE I. Statistics of NATIONAL LANDSCAPE GARDEN COUNTIES IN GEOGRAPHic REGiONS

\begin{tabular}{ccccc}
\hline Geographic area & $\begin{array}{c}\text { Number of National Landscape } \\
\text { Garden County }\end{array}$ & Ratio (\%) & Cumulative ratio (\%) & Rank \\
\hline East China & 83 & 28.53 & 28.53 & 1 \\
North China & 53 & 18.21 & 64.95 & 2 \\
North-west region & 53 & 18.21 & 46.74 & 4 \\
Central China & 43 & 14.78 & 79.73 & 5 \\
Southwest Region & 41 & 14.09 & 93.82 & 6 \\
Southern China & 9 & 3.09 & 96.91 & 6 \\
North-east area & 9 & 3.09 & 100 & \\
\hline
\end{tabular}


TABLE II. Statistics of NATional LANDSCAPE GARdEN COUNTIES ON THE PROvincial Basis

\begin{tabular}{|c|c|c|c|c|}
\hline Province & Quantity(number) & Ratio (\%) & Cumulative ratio (\%) & Rank \\
\hline Hubei & 27 & 9.28 & 9.28 & 1 \\
\hline Shandong & 26 & 8.94 & 18.22 & 2 \\
\hline He'nan & 25 & 8.59 & 26.81 & 3 \\
\hline Shaanxi & 23 & 7.90 & 34.71 & 4 \\
\hline Yunnan & 19 & 6.53 & 41.24 & 5 \\
\hline Xinjiang & 19 & 6.53 & 47.77 & 5 \\
\hline Shanxi & 17 & 5.84 & 53.61 & 7 \\
\hline Chungking & 16 & 5.50 & 59.11 & 8 \\
\hline Zhejiang & 14 & 4.81 & 63.92 & 9 \\
\hline Anhui & 13 & 4.47 & 68.39 & 10 \\
\hline Hubei & 12 & 4.12 & 72.51 & 11 \\
\hline Jiangxi & 11 & 3.78 & 76.29 & 12 \\
\hline Jiangsu & 10 & 3.44 & 79.73 & 13 \\
\hline Fujian & 9 & 3.09 & 82.82 & 14 \\
\hline Inner Mongolia & 8 & 2.75 & 85.57 & 15 \\
\hline Guangxi & 8 & 2.75 & 88.32 & 15 \\
\hline Hunan & 6 & 2.06 & 90.38 & 17 \\
\hline Sichuan & 6 & 2.06 & 92.44 & 17 \\
\hline Ningxia & 6 & 2.06 & 94.5 & 17 \\
\hline Gansu & 5 & 1.72 & 96.22 & 20 \\
\hline Jilin & 3 & 1.03 & 97.25 & 21 \\
\hline Beijing & 2 & 0.69 & 97.94 & 22 \\
\hline Liaoning & 2 & 0.69 & 98.63 & 22 \\
\hline Heilongïiang & 2 & 0.69 & 99.32 & 22 \\
\hline Tianjin & 1 & 0.34 & 99.66 & 25 \\
\hline Hainan & 1 & 0.34 & 100 & 25 \\
\hline Shanghai & 0 & 0 & 100 & 27 \\
\hline Guangdong & 0 & 0 & 100 & 27 \\
\hline Guizhou & 0 & 0 & 100 & 27 \\
\hline Tibet & 0 & 0 & 100 & 27 \\
\hline Qinghai & 0 & 0 & 100 & 27 \\
\hline
\end{tabular}

C. Spatial association pattern of National Landscape Garden Counties

The estimated index value of Global Moran's I of the spatial distribution of National Landscape Garden County is 0.1867 and the normal statistic is 2.02 . The index values are all positive. These indices are greater than the critical value of 1.96 at a confidence level of 0.05 and passed the significance test. It shows that the distribution of National Landscape Garden County has obvious spatial autocorrelation characteristics, and the provinces with the same number of named county cities tend to agglomerate in space.

From the Moran scatter plot (Fig. 4), the number of provinces in the first and third quadrants is 10 and 7, which together account for $54.84 \%$ of the analysis units, of which the province in the first quadrant accounts for $32.06 \%$. It is reflected that the spatial distribution of National Landscape Garden County is more positively related, and the spatial association of neighboring provinces is more indicative of a High-High clustering model.

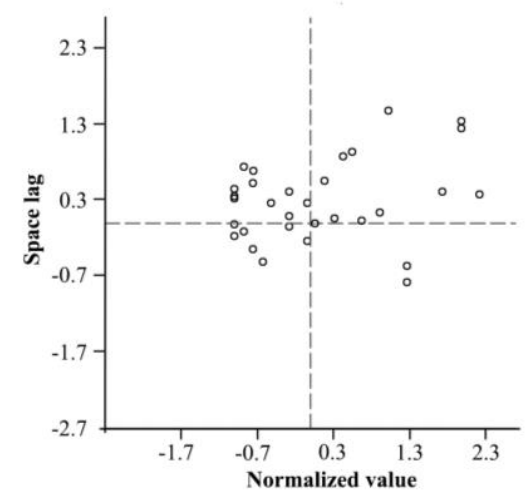

Fig. 4 Scatter Plot of Moran 
The Getis-Ord Gi* index was further calculated, and 31 analysis units were divided into 4 categories using the Jenks natural break point classification method in ArcGIS 10.2 to generate the hot and cold district map of National Landscape Garden County (Fig. 5). The figure shows that: (1) The number of hot spots is the largest, with 10 , and they are clustered in the central and eastern regions of China; There are 7 sub-hot spots and their locations are close to and around the distribution of hots pots; The above both form a contiguous, high-valued cluster.(2) There are 9 sub-cold spots, all connected with the sub-hot spot; The number of cold spot areas is lowest, only 5,Including one cold spot agglomeration that composed of three provinces in South China and two isolated cold spots in Heilongjiang and Qinghai; The low-value clustered areas formed by the two are mainly distributed along the coast and the edge.(3) As a whole, the "core-periphery" structure of the spatial association pattern of National Landscape Garden County is obvious, showing the characteristics of changing from hot to cold and gradient.

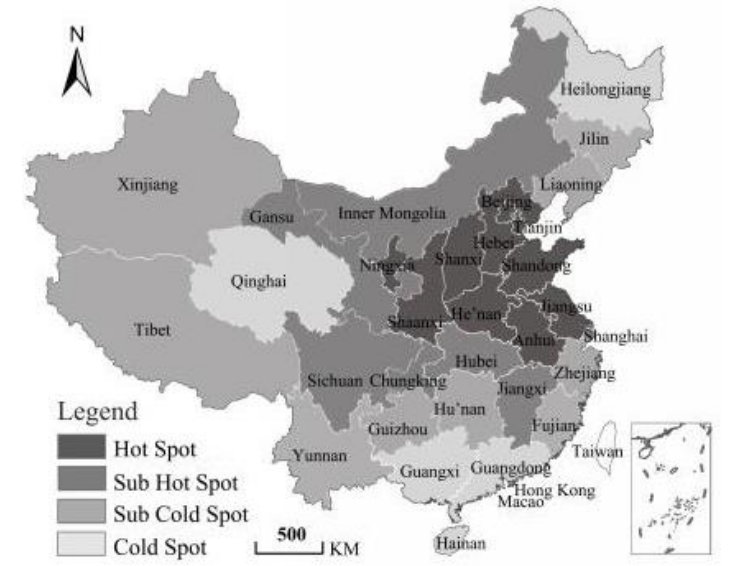

Fig. 5 The Hot and Cold District Map of National Landscape Garden Counties

\section{CONCLUSION}

(1)National Landscape Garden County has a significant spatial concentration, forming three high-density distribution areas in Luzhong, Longnan and Guanzhong areas.

(2)There is a scale effect in the equilibrium of the distribution of National Landscape Garden County, which is represented by the average distribution from the regional scale to the uneven distribution of the provincial scale.

(3)The distribution of National Landscape Garden County has significant autocorrelation features both globally and locally. The "core-periphery" structure of the spatial association pattern is obvious, and it shows a pattern of changes from hot to cold and gradients.

\section{REFERENCES}

[1] BAO C, CHEN X J. Review and prospect of research on the spatial pattern of China's urban system [J]. Progress in Geography, 2014, 33(10): 1300-1311.

[2] XU X Q, HU H Y, ZHANG J. Several characteristics of urban distribution and its evolution in China [J]. Economic Geography, 1983, 3(3): 205-212.

[3] YAN X P, WANG L. A study of the changes of the spatial pattern of Chinese cities since the reform and open policy [J]. Human Geography, 1996, 11(3): 19-23.

[4] YE H, PU L J, ZHANG P. Spatial distribution pattern and its evolution of urban system in China [J]. Areal research and development, 2013, 32(2): 41-45.

[5] GU C L, PANG H F. Evolution of Chinese urbanization spaces: Kernel spatial approach [J]. Scientia Geographica Sinica, 2009, 29(1): 10-14.

[6] JIN S T, LI B, YANG Y C, et al. The distribution of cities in China and its influencing factors [J]. Geography Research, 2015, 34(7): 1352-1366.

[7] GUAN C M, CUI G H. Research on spatio-temporal distribution of Chinese cities in the past over 100 years [J]. Areal research and development, 2004, 23(5): 28-32.

[8] WU J S, LIU H, PENG J, et al.Hierarchical structure and spatial pattern of China's urban system: Evidence from DMSP/OLS nightlight data [J]. Acta Geographica Sinica, 2014, 69(6): 759-770.

[9] YE D N, HE W, XU W D, et al. Symmetry distribution of cities in China [J].Science in China(Series D), 2001,44(8):716-725.

[10] YE H, PU L J, ZHANG P. Inter-provincial differences and its impact factors of urban spatial distribution in China $[\mathrm{J}]$. China Population, Resources and Environment, 2012, 22(12): 159-164.

[11] RUI Y, TANG B P, WANG X, et al. The spatio-temporal evolutionary characteristics and the impact mechanism of national garden cities in China [J]. Geography Research, 2018, 37(1): 20-36.

[12] XIE Z H, WU B H. Tourism spatial structure of resources based attractions in China [J]. Scientia Geographica Sinica, 2008, 28(6): 748753.

[13] GAO C, JIN F J. Spatial pattern and industrial characteristics of economic technological development areas in eastern coastal China [J]. Acta Geographica Sinica, 2015, 70(2): 202-213. 